\title{
Quantifying Ocean Currents as Story Models: Global Oceanic Currents and Their Introduction to Global Navigation
}

\author{
Agnes Kneitz
}

l The Charts of the Currents, or What This Work Is Designed to Illustrate as Follows

'They were toys destined only to bob up and down in nothing bigger than a child's bath-but so far they have floated halfway around the world', rhapsodized the Daily Mail in June 2007 when an armada of yellow rubber ducks was to reach the shores of Cornwall and southwest Wales (Clerkin 2007). Since their containers had fallen off a container vessel in the Eastern Pacific in 1992, the little floaters had gone on an incredible journey that certainly inspired lots of sailor's yarn, but actually revolutionized ocean science. They enabled researchers to track global ocean currents, and learn about the interplay of currents and gyres on a global scale, and are thus a colourful example of happenstance

\section{A. Kneitz $(\square)$}

Renmin University of China, Beijing, China

A. Kneitz

Rachel Carson Center for Environment and Society, Munich, Germany

(C) The Author(s) 2018

M. Perez Garcia and L. de Sousa (eds.), Global History and New

Polycentric Approaches, Palgrave Studies in Comparative Global History, https://doi.org/10.1007/978-981-10-4053-5_10 
turning into scientific evidence (Hohn 2007). In this case, it was oceanographer Curt Ebbesmeyer's curiosity that inspired him to follow in the footsteps of early researchers such as Admiral Alexander Becher, who used strategically placed bottle messages to gather information about gyres in the early 1800s. Apparently, Becher himself was inspired by two maps of sub-tropical gyres published by the British geographer James Rennell in 1822 (Ebbesmeyer 2009: 156).

Early ocean navigators relied on observation based on knowledge about global currents and wind patterns. Balancing on the shoulders of Galileo or Bacon, sailors and mariners later measured, experimented, calculated, and initiated more measuring, experimenting and calculation (Petterson et al. 1996). A unique scientific culture developed from increasing communication between naval professionals and lay scientists, based on seventeenth-century experimental work in European natural philosophy. But influenced by global commerce, currents needed to be mapped and understood more accurately, as they influenced the safety and outcome of (trade) expeditions. Such a largescale undertaking required the study of multiple widespread but interconnected phenomena, a practice that would become known as Humboldtian science (Dettelbach 1996). Previously, such data existed merely as eclectic pieces and without systematic framework in both the Western and Eastern hemispheres. Only the publication in 1832 of James Rennell's Investigations of the Currents of the Atlantic Ocean argued for a systematic approach based on modern scientific methods. This included the first comprehensive model of global ocean currents, but still advocated for floating body experiments (Rennell 1832: 35). However, the subsequent physical scientific understanding of the oceans as a complex system (Reidy 2008) has no equivalent in Chinese science (Needham 1971: 560).

From the Qin dynasty onwards, Chinese geographers produced accurate maps of terrestrial waters that find no equivalent in Western natural history (Needham 1959: 514ff); however, ocean waters seem to have been of no importance to them. And despite astrological explanations for water movement in rivers, they mostly displayed an animistic worldview (Needham 1959: 488). Influenced by the mechanistic worldview of the Enlightenment, Benjamin Franklin mapped the Gulf Stream in 1768 (Chaplin 2007), and Jean-Baptiste Lamarck published a Hydrogéologie in 1802 arguing that global ocean currents flowed from east to west, thereby moving the continents (Carozzi 1964), obviously reminiscent of Anastasius Kirchner's Mundis Subterranaeus (1665) that described underground channels to keep the earth's waters circulating around the globe. 
Rennell proceeded to explain links between individual currents in relation to wind and weather systems as well as land masses and sea beds. Available observational data and his insightful knowledge then began to constitute a predicative system. However, his desired comprehension required stories or pictures - something equivalent to a model—as such data would make a better impression as 'a part of system, which operates like a band to keep the parts together in their proper places' (Rennell 1832: 17).

Although Rennell's Investigations presented a global model of the ocean currents, it relies on maps and data of the Atlantic and the Indian Ocean. He then extrapolated his observations onto a global scale. His main sources were his own travel accounts, supported by information from British sailors and navy officials (1832: 286). There is little data from the Arctic region that was sailed primarily by Russians (Williams 2013: 132f). Another grey area is the Pacific Ocean, for which most data would be held by Portuguese, Spanish, and Dutch sailors. Even after James Cook's voyages, data from that area remained less diverse. Following the end of the Napoleonic Wars, geographical eurocentrism was then re-defined by re-evaluating Europe and thus the Atlantic as the great theatre of world traffic and world history (Rupke 2001: 112f). Geographically, the Pacific itself supported the common perception of the Atlantic as 'Cultural Mediterranean': a wide body of water provided navigational obstacles. In early Chinese sources, this is attested to by describing the oceans - as compared to the navigated 'China Seas'—as frontier and mythical places alike (Schottenhammer 2012: 67). However, access to data about the 'China Seas' became limited by the seventeenth century. It is thus no surprise that there is no mention of China in Rennell's Investigations.

Yet Chinese and early modern European sources both apply bodily metaphors to describe larger systemic connections (Needham 1959: 487). Rennell presents complex patterns of flow, including swirls and eddies and side-streams on a global scale. But he translates his findings into a comprehensive account of accessible lay experiences rather than scientific jargon. This chapter is interested in how his model differs from earlier natural historical descriptions of the oceans, and why there might be no Chinese equivalent to his work. What role does the linguistic shift play in natural sciences that separated laymen and scientists as well as Eastern and Western professionals? How is it related to the development of scientific culture and practices? His way of arguing foreshadows modern issues of public trust in science-especially those studies with a global approach and impact. Is his work an example of broadening traditions? 
Does it advocate a natural scientific 'motivation' for ocean research or is it a medium of communication? The Investigations accounts for China's absenteeism in global scientific development that was reinforced over the course of the nineteenth century. Can Rennell's work stand as a symbol of a partition of the world in two or more spheres on the basis of its oceans (Reinhard 2014: 66) that would only be overcome by the midtwentieth century?

\section{Embarking From Qualitative to Quantitative SCIENCES}

James Rennell researched the geography of India and Africa, acting as an 'independent expert' on behalf of the British Navy, before he settled on hydrograpy. His affiliation flags the intimate connection between ocean science and economics, while accounting for the Atlantic-centrism of his global model. Both are a result of the imagination of inexhaustible natural wealth that originated from the discovery of a Second Earth in 1492 and what would ultimately result in an economic division of the world with the Atlantic at the centre (Worster 2016). China, which had been ahead of Europe in many areas-including nautical sciences-only tasted the benefits of the new world's resources through trade expeditions via the Indian Ocean, until the gap between Eastern and Western hemisphere had become almost insurmountable (Pomeranz 2000). Dividing the world into spheres of economic dominance and broadening their differences into metaphorical faults devalued transient waters like the Indian Ocean that had connected East and West as part of the maritime silk road for centuries (Ptak 2007: 78f). This applies to nautical scientific development and global ocean exploration at the same time. And the Indian Ocean had become gradually linked to the China Seas since the Sui dynasty (Ptak 2007: 54).

While studying the currents of the Atlantic, monsoons, trade winds, gyres and their influence on the drift of the ocean, Rennell developed his own practices of analysis and observation (Griffiths 1993), as well as an iconography for 'streams of currents'. Borrowing from Protolan maps that bore a close resemblance to Chinese coastal maps (Needham 1959: 560), he depicted currents as bodied entities of water. On each side, bounded by parallel lines of split arrows, this credits to how he had recorded his surveying on the rivers of India (Bravo 1993: 45; Rennell 1781). His 1778 Chart of the Bank and Current of Cape Lagullas is 
based on data he collected travelling back from Bengal (Pollard 1993: 25 ) and provides insights into shifting practices of proto-scientific data collection that would unfold in the mid-1830 s in tideology (Reidy 2008: 157). As Charles Batten suggested in 1990, the systematic coordination of Rennell's studies of winds and currents had at this point of time just created the need to establish the field of oceanography (150).

With the absence of technological precision equipment, Rennell's friends, like Admiral Beaufort, William Bligh or Tremayne Rodd and their logbooks were his main source of data (see Rennell 1832). They provided a basis for analysis, and with their reputations added credibility to his work. An Investigation of the Currents of the Atlantic Ocean, and those which prevail between the Indian Ocean and the Atlantic consists of seven annotated charts of winds and currents, based on an immense store of material, which was systematized by 1810 and continually revised for more than 20 years. Claudine Salomon mentions a deviationist of Chinese map-makers, Chen Lunjiong, who used the same method to collect data compiling a coastal map that would contain tidal times and wind directions in the late eighteenth century (Salomon 2006: 182). In their general appearance, Rennell's maps resemble Alexander von Humboldt's 1817 isoline technique for spatial distribution maps that were crucial to initiating the spacial turn in geography. These maps evolved with a significant epistemic shift (Rupke 2001: 115), signifying a harmonious unison of quantitative and mathematical cartography. In developing their work, both Humboldt and his cartographer mainly subscribed to the Rennellian concept of ocean circulation (Peterson et al. 1996: 64) and both parties employed British Navy data (Reidy 2008: 196). After a visit to London in 1827 and the acquisition of Rennell's papers, Humboldt encouraged Berghaus to prepare illustrations for his Kosmos that resemble the former's ocean currents (Rupke 2001: 95). As Kortum (2001: 94f) has laid out, Humboldt cites Rennell several times in his opus thereby attesting for the fruitful correspondende of the two researchers.

Rennell considered information from trustworthy sources only, treated it as a statistical average and most importantly reflected on sources of error, while spending much time discussing them (Rennell $1832,162)$. Therefore, his acquisition of data reveals a modern understanding of scientific methods, and one that was mirrored by other emerging field sciences, such as meterology (Anderson 2007). In his book on the inclusion of intuition and induction in scientific thought, Paul Merderwar echoes Rennell, arguing that science 'comes not from the apprehension of facts, but from an imaginative preconception 
of what might be true' (Cornell 2013: 442). This kind of imaginative rending is true in the sense of being consistent with available observations. Models by themselves are just stories, just as data without models is mere numbers. Rennell, however, was both observer and modeller, which allowed him to self-validate the consistency of its idealized global ocean model. To solve persisting problems with scientific accuracy, he continuously acquired and revised data, and referenced his sources. Technological progress enabled him to integrate even more data (i.e., measured with chronometers) and to juxtapose it with previously collected traditional data (Bravo 1993: 46).

The influence and value of his work is reflected in its attribution by Humbold or Berghaus, and its relative validity for more than a century (Gould 1993: 28), the accuracy of his data adds credibility from a modern point of view (Schrier and Weber 2006: 10f). As he stated himself, 'the work at large will meet the appropriation of those who are competent judges of it' (Rennell 1832: 15). This further reflects awareness of a possible rejection by a scientific community that was entangled in internal struggles of hegemony at the time (Cawood 1979). Doubtless, his work was important, but the increasing emphasis on exploring the Arctic required differently precise data to secure of ships and crews (Millar 2013: 78). Rennell's prose reveals strong responsibility for the safety of his fellow seamen, and he saw potential in combining old and new practices to enhance it. In discourses within the Royal Society, he especially advanced the argument of mechanical perfection: the compass was the 'heavenly gift' on which 'the lives of so many brave and useful men often depend'. ${ }^{1}$ But research and publishing opportunities for naval officers were few, and hydrography (like metereology) was not considered a formal science.

Considering this period a scientific 'Sattelzeit' in Kosellek's understanding, it technologically materialized in iron ships and their material qualities challenging the security of both expeditions and data. In a trend of standardization, lay practitioners then replaced their south-pointing compass needles from the Chinese tradition (Needham 1962: 330ff) with the mariner's north-pointing ones. By aligning Western techniques, errors in data acquisition deriving from heterogeneous practices were slowly being obviated. However, this homogenization reinforced a scientific Western-centrism and resembled a technological enforcement of Eastern and Western spheres of knowledge. But in both of them, the ocean stood for uncounted mysteries and Rennell sensed that his work was still fragmentary. Concerning his model of the North Atlantic current, he wrote that: 'Materials are wanting for the filling up of one large 
proportion of this great extent of the course; nor is it surprising considering the vastness of the whole' (Rennell 1832: 406), which also attests to his awareness towards limited accuracy in his scientific method.

As Sarah Cornell points out in her commentary on the Investigations, good model-making requires intuition and imagination, which Rennell demonstrates when imagining for his reader 'a globe covered with water' that would be affected by opposing trade winds and currents, merging into a broad stream 'along both sides of the Equator, round and round the globe for ever' (Rennell 1832: 127). But as the actual globe is broken up into pieces with landmass predispositions, obstacles and other irregularities, these would necessarily be taken into account allow for the real-life applicability of his model. The already emerging nineteenth century saw increasing motivation to quantify and model nature for modern natural scientific purposes. At this epistemological turning point, Rennell's model seems a hybrid: still representing geopolitical hopes for sea power (Baugh 1990: 42), while combining antiquarian and modern practices of data collection (Bravo 1993: 41).

\section{Practices of Data Collection and Knowledge Production}

As much as Rennell witnessed radical changes in politics and ideology, he witnessed shifts in scientific philosophy and practice. While the 'scientist' emerged as a new being (Reidy 2008: 236), but was abstracted from his discoveries (Schaffer 1986: 412), isochronal focus on mathematics and physics entailed precise language for expert communication, and technological advancement led to accurate instruments (Miller 1986: 119). These possibilities manifested themselves during the aftermath of experimental philosophy's 'cornucopia' after the Renaissance, which marks the transition from quantitative to mathematical ways of investigation, but which does not find an equivalent in Chinese science (Needham 1971: 559). Considering the broad scope of scientific change during the Sattelzeit, the accumulative power and creative force unleashed with the end of absolutism was forceful. Since the mid-seventeenth century, the notion of doing something 'carefully' had already broadened the meaning of doing something 'accurate' to that of 'being exact'. Concurrently, the (mental) abstraction of 'precision' became part of scientific language. Due to these linguistic shifts, studies and analysis from the mid-eighteenth and nineteenth centuries seem worlds apart. Rennell translates between these practical and scientific worlds from which nautical data was drawn. 
Translating between practical and scientific sources, the hydrographer acknowledged the possibility of errors in this new discourse, considering that new instruments could also be inaccurate. This is notable, as this meant it was Rennell as a representative of what had become considered the 'faulty human element' during the Enlighthement's sparking technooptimism, who still provided balance between the differenent practices of data acquisiton. Considering this source criticism a sign of quality management, his work reflects high standards also in his awareness of the limited accuracy of his own method and the grey areas for missing data. Both problems would be addressed carefully by the following generations of scientists, especially by filling knowledge gaps with data available through international research cooperation and precision instruments. Unlike during medieval times, when the concept of the magnetic compass was passed on from China to Europe via the Indian Ocean, the knowledge of the Eastern hemisphere was not tapped into at this point (Needham 1962: 330).

Matthew Fontaine Maury wrote on winds and currents in the North Atlantic, where his predecessor simply lacked data due to technical and polito-lingusitic obstacles (Gould 1993: 29; Williams 2013: 132f). In comparison, the situation in the 'China Seas' differed not as significantly as the 19th century believed: The 'Asian Mediterranean' was a place of vibrant economic and cultural exchange (Zurndorfer 2016: 66). But climatically, it was influenced by seasonal monsoon winds, whose existence had been reported since the Han dynasty (Schottenhammer 2012: 67); but no systematic description would have been accessible to Rennell. Similarly, integrating foreign language data on the 'Silent Ocean' seemed unlikely in the context of European domination. Supporting the recovery of a sea-wrecked steamer in 1852, Maury introduced knowledge about ocean circulation into the ocean of circulating knowledge on ocean circulation, as Julia Heunemann phrases it (2014: 150). Chinese navigation still relied on junks that would only slowly become replaced after the Opium War (Granados 2012: 95). Both Maury's and Rennell's work became possible with the invention and availability of chronometers that made it possible to measure weaker currents from around 1800 (Charnock and Deacon 2001: 155). As Rennell stated himself, this fostered the systematic collection and analysis of data (1832: 10). Previously, the Chinese physical sciences had provided comparably prescient measurement techniques. But with their stagnation after the Kangxi 
emperor (Needham 1971: 555), these practices seemed outmoded compared to Western precision instruments, despite their accuracy.

The next oceanographic model, featuring the relationship between the distribution of marine organisms and deep-sea temperature, originated from William B. Carpenter's curiosity to further investigate Rennell's groundwork. Instrumental in organizing the 1868 Challenger Expedition, Carpenter is an example of a late naturalist engaging in debates around physical science exploration, trying to align and finally standardize the skills and ambitions of mixed research groups along shared research programmes (Miller 1986: 107). He developed a theory of ocean currents being driven by differences in water density, but it was considered insufficient, neglecting the importance of wind patterns (Heunemann 2014: 156). Within a few decades, technological process enabled more 'precise and accurate' observations of ocean temperature and water density. From the Challenger Expedition onwards, the depth of the ocean was recognized to influence cold weather originating from the surface in the polar regions (Deacon 1997: 310-348). Although these studies built on the Investigations, there is no evidence that Rennell considered the layers of oceanic waters beyond the common understanding of a cover stratum over a deep unknown (Schlee 1973).

Later observations depended on the quick advancement of technology, increasing international exchange and oceanography becoming a truly global field of inquiry. The German Meteor Expedition to the South Pacific (1925-1927), for example, used early sonar to identify a broad meridian convective cell as forging sinking polar water towards the equator. But it took American Henry Stommel until 1948 to rectify their errors. At the same time, virtually no direct measurements of currents below the surface were taken until 1950 (Heunemann 2014: 157). This again showcases the connection between the advancement of technology, pushing the frontiers of knowledge and the wider expedition radius. Rennell had already acknowledged this mutual dependency and the resulting limitations for his work. In his first hydrographic study, he had analysed the Agulhas Current around South Africa separately, but never touched upon areas further south, which he identified as imperfectly known; so that generally, between 30 and 40 degrees of latitude, and longitudes $25^{\circ}$ and $40^{\circ} \mathrm{W}$ is nearly a blank on the chart' (Rennell 1832: 280). His later index map visualized how that gap of knowledge south of the Southern Connecting Current had not been closed during his lifetime. 
Conducting seminal research on individual currents, questions of water quality or other local (less global) qualitative and quantitative aspects, Rennell furthered germinating oceanography (Rodd 1930: 296). His model of a global oceanic body of water allowed for a new systematic approach, making it possible to integrate local data into global charts while deducting generalized statements. It also highlights the uses and benefits of scientific models, while identifying levelled scientific development as a precondition to accurately designing and calculating them. Great advancements had been made over the seventeenth century, even without modern precision standards for scientific equipment (Howse 1990: 183). However, chronometer and improved methods to measure longitude at sea allowed Rennell and his epigones to collect accurate, if not reliable data (ibid., lf). But most importantly he visualized logbook data and annotated this new source of information, making it accessible to both marine practitioners and landborne scientists.

\section{Changes in Scientific Values and the Perception of Nature}

During the Sattelzeit, the meaning of the term 'precision' depended on its application in scientific language. Different meanings invited for comparison and-arguably-licensed multiple terms of reference. Since James Cook's pacific encounters, when (lay) scientists and even artists became a permanent feature of British naval explorations, the terms 'precision' and 'accuracy' could refer to a person's habits of observation, their care and trustworthiness. Alternatively, if a traveller corrected a natural philosopher's previously made descriptions, this assessment was regarded as more 'precise'. This indicates a qualitative increase through multiple opinions, but more importantly through data collected with state-of-the-art technology and methods. In the Chinese tradition, geographers and travellers had played a similar role for knowledge acquisition since the fourteenth century. And like 'travel books' and 'natural histories' compiled by Western travellers, their accounts eventually resulted in a specific genre of 'maritime travel literature', shaping perceptions of the oceans (Ptak 2007: 211). Despite advanced knowledge in astronomy and physics, they were greatly infused by cosmological and mystical elements (Needham 1971: 563), which finds its equivalent in fantastic creatures decorating Western maps or fictional descriptions of alien environments. 
Even more so, the Western authority of 'precise knowing' owed much to the design and construction of quadrants, sextants, chronometers and other technical equipment (Baugh 1990). And this authority grew and strengthened quickly over the nineteenth century, when materials were more finely harnessed towards perfection in their geometric division and measurement. While Chinese sciences were 'sabotaged' by political and social instability, the West began to think in larger volumes of data and even more dimensional layers (Corbin 1994: 106). The capacity of the term 'precision' to sanction authority in these multiple contexts gained considerable rhetorical force, as 'the gentlemen [scientists] clothed themselves in the language of precision' (Bravo 1993: 164) and the elasticity of the term lent itself to extensive usage. Yet it retained specific, tangible meanings, which for the scientific traveller continued to rest on reliable work habits (Williams 2013: 124). Retrospectively, the terms had substantially different social origins (Bravo 1999: 163), and when oceanography became fully fledged in the 1880s and 1890s, it 'was hardly a discipline that shared a common set of intellectual questions, nor is it today. Rather, it was (and remains) a science that focuses the attention of many physical, chemical and biological fields on the project of understanding a geographic place' (Rozwadowski 1996: 409).

In order to combine these areas into a common knowledge space, practitioners required literacy in more than one discipline, but as a group they were even more defined by the act of going to the sea (Rozwadowski 2008). This shift in practices and attitude as a response to the transition from quantitative to mathematical observation and cartography is not attested to in the Chinese sciences. Like the Western seamen, the Chinese also required steady conditions to conduct astronomical measurements, although their early reliance on the magnetic compass had made them independent from most weather conditions. The importance of this object features in the traditional name for the navigation officer, which translates as 'person in charge of the light' (Gang 1997: 40). Being unaffected by the Western scientific revolution, Eastern seafaring still relied on time-and field-tested practices that also did not require changes in map-making. However, the seventeenth-century Western-inspired geographical representations on Chinese maps represent the intellectual dilemma of incorporating humanist ideas from the 'Far West' (Ptak 2006, 2007).

Only with the beginning of the nineteenth century were gradual shifts towards accuracy in a Western sense recorded in both cartography and 
maritime technology. These were connected to the defensive strategy of securing Chinese borders and waters against increasing piracy, smuggling and foreign intrusion along the south coast. Before such threats in the 'maritime frontier area' (Salomon 2006: 178), Protolan-style maps had been sufficient tools for navigation as ocean exploration had been abandoned after Zheng He's travels and Chinese maritime involvement focused on coastal waters. But even for overseas trade with Asian partners, a refined method of compass use made technological and cartographical innovation obsolete. Only the adaption to Western-style ships finally required or inspired changes in navigational practices that became visualized in the commonly used coastal maps.

Mechanized instruments and heavier more stable ships gradually counterbalanced the 'faulty human element' that became free to engage in evaluating and interpreting data, from which it was actually practically and cognitively separated (Schaffer 1986). For Rennell and his peers, the new relationship with seemingly homogenous information on different scales and different places was still to be revealed. But according to Bravo, a delay in changing practices and habits was the actual problem for natural science to remain in its pre-stage (1993: 166). Similar circumstances may have applied to Chinese maritime navigation, as it only deferred to struggle for technological competitiveness in view of foreign ship building that forced to alter military and economic considerations (Granados 2012: 104). This left little room for scientific ambitions. Linking the Pacific Theatre to Asia and Africa, the further influenced the relationship between the concepts of curiosity and precision in scientific research. Fundamental linguistic and related changes in methodology during the eighteenth century are crucial to understanding those in the nineteenth century, as they concern both the motivation to collect marine data as well as associated social and scientific practices.

Francis Bacon's essay on travel, for example, emphasizes procedures like keeping a journal and making topographical sketches as antecedents for the later European expansion in the Pacific (Deacon 1997: 15). When Europeans began to venture into the waters between Asia and the Americas, they gradually took over the roles formerly operated by Asian traders and with this opened up the 'China Seas' (Schottenhammer 2012: 83ff). Cartographers in the East, on the other hand, had begun to integrate Western standards since Matteo Ricci (Ptak 2006: 206). Maps were predominantly individual, safely kept possessions, but although maps were predominantly individual, safely kept possessions, Rennell's new annotated compilation resembles the eighteenth-century Nautical 
Almanach (Miller 1983: 18ff). For him, logs were artifacts of similar quality, and each navigational chart was accompanied by a memoir to enhance its accessibility. The only Eastern Empire that had comparably reliable scientific information on global navigation had destroyed it after the expeditions of Zheng He (Schottenhammer 2012: 65).

Reflecting both political consciousness and research skills, this understanding was Rennell's keystone for putting his ideas about precision into practice. Methodologically, his Investigations were designed to make information processing accountable and transparent, and therefore adopted high-quality cartographic conventions of toponym and source citation. In the process of integrating and showcasing new techniques, practices of knowledge acquisition and distribution, he kept his model close enough to traditional standards to secure its acceptance among professionals. In juxtaposition, these practices minimized errors, as 'the differences in northing and southing, between the dead-reckonings and observations', for example, 'might be pointed out by the observations of latitude, yet the error of longitude, of easting and westing, would, of course, escape detection altogether' (Rennell 1832: 10f). With his dual expertise, he carefully synthesized the material and provided general assumptions.

A subjective notion of 'trustworthiness', based on curiosity and precision can be interpreted as characteristic of modern science. With technological advancement and disciplinary specialization, however, the means of generating credibility were altered in response to the changing attitudes of lay and professional audiences (Reidy 2008: 247). Progressing change in Western scientific values therefore focused on mathematical calculation and scientific modelling (Miller 1983: 14f). At the turn of the eighteenth century, it lay within reach to measure the world as a whole, which Humboldt attempted to in his Kosmos. Mathematics had just entered the field, providing a new language for its representation (Reidy 2008: 55). However, for Rennell's model of global ocean currents, the growing influence of Newton and Bernoulli was ambivalent, as they perceived the oceans as an equilibrium, leaving no space for their flows.

\section{Models Are Stories: Shifts in Narratives}

Rennell's currents visualized cartographers' 'rough work' and demanded they disclose their sources. They emphasize the necessity of explaining rationales while distinguishing between those areas of a map that are demonstrably 'true' and those interstitial spaces that are merely coincidental and empirically unsubstantiated. This communication process 
required learned travellers, armchair geographers and reviewers to incorporate cartographic conventions in their repertoires (Rupke 2001: 93f). Here, Rennell's work fostered information exchanges between laymen and savants, otherwise, ignorance of accuracy conventions invited censure from fellow travellers, editors, mariners, etc. The Investigations further provided a new vocabulary and methodology that helped to produce more credible and precise accounts, again improving popular scientific communication.

In terms of offering modelled insights on a globe covered with water, Rennell explained the difficulties for contemporaneous oceanographic science as follows: 'one might expect, that the opposite trade-winds would impel the surface waters, subject to their operation ... But as our globe is terraqueous, and the land broken into an endless variety of forma [sic!] and positions, those gently moving surfaces, which would, in the other case have flowed so smoothly and uninterruptedly, are here interrupted in various ways; and, accumulating into different streams, are projected in such directions, as the positions of the several obstacles necessarily produce' (1832: 127). There was yet no satisfying solution to analysing an object that was so strongly influenced by different kinds of physical materiality. In naturalist tradition, Rennell treated the river systems of India as special cases of mapping continental coastlines in order to add them to the British network of navigable sea routes that closely resembled Chinese sources (Needham 1959: 487). Yet he immersed himself in natural science over the years, a professional act of adaptation to changing practices and scientific requirements, but supported by his personal method, and interest in physics and experimental equipment (Griffiths 1993: 37).

Precision and accuracy were important for Rennell. His frequent referencing a variety of oral sources features the Investigations as a historical text filled with social energy (Greenblatt 1988). By contrast, it exposes how today's scientific writing (that pursues the ideal of 'objectivity') risks to become dehumanized to an almost problematic extent. Rennell thus not only explicitly names his informants, but also refers to his own professional and personal experience, almost foreshadowing the attention modern scientists ascribe to 'contributory' expertise. His background not only equipped him with the availability to see beyond 'naked standing facts' (Rennell 1832: 5) and integrate them into a larger picture, but assigned credibility in front of his increasingly diverging target audience, almost like a collective travel-log, from which scientific data is retrieved, and which is framed with more or less personal experience as visual aids (Rennell 1832: 262). 
Scientific writers, beginning with Franklin, employed organic and bodily metaphors increasingly through the nineteenth century. Like Rennell, considering the causes and effects of different currents to describe the ocean as a body is moved by different forces (Rennell 1832: 57). 'A great enlightened [organic] machine, whose prime movers were some main currents by the aid of adjunct waters [and winds]' (Rennell 1832: 48)—a narrative that accounts for the still-dominant mechanist view of nature. But in his methodological borrowing from geography, as in modelling oceans after continental rivers, he contemplates how 'a sea current is not like the stream of a river, which passes on its way to the sea, but rather like one that should finally spread its waters over a level of a country, in [the] form of a lake' (Rennell 1832: 530). This seems to be an allusion to more holistic understanding of nature. But while striving towards accuracy and precision, scientists admittedly romanticized the sea and seafarers: steamships replaced sailing ships and this transition was reflected in popular narratives about the world's oceans (Rozwadowski 2008: 216).

\section{Enlarged Descriptions and Details of Several CONCLUSIONS}

The 'Sattelzeit' natural sciences saw changes in technology, motivation, culture and politics of marine knowledge production, like oceanic swirls and eddies and side-streams that can almost be read as tropical for the various twists and turns within the scientific community. Here, Rennell embodies a community of naval officers and marine laymen in personal union with natural scientists. And to a certain extent, he challenged or at least restructured the existing traditional order from which a new scientific maritime culture emerged. Yet he represents the Eurocentric perspective on the world's oceans that had established itself with Western dominance in world economic relations since the discovery of a Second Earth. The congruent (self-)perception of European scientific superiority seems to reinforce itself by abandoning Eastern-inspired practices of navigation, like the reintroduction of the dry pivoted compass to China by Portuguese and Dutch merchants via Japan from the sixteenth century onwards (Needham 1964: 334).

The Investigations exhibits the power of quantification and systematization, providing both a rich description of the ocean's large-scale behaviour and weighing its exhortation to apply its compiled knowledge 'to avoid or delay danger' (Rennell 1832: 12). Its predictions of maritime 
currents and their hazards were valued and taken seriously by navigators and scholars alike. However, by today's standards, the evidence base relies on too few numbers and even precarious ones: the record of ship's logs is incoherent and is supplemented by occasional records of bottle landings and bits of shipwrecks washing up on beaches. It is also noted how the assumed correctness of the chronometer was ascertained by lunar observations. The technology Rennell used corresponds with Western standards that had long forgotten their Chinese origins, and his quantification and systematization produced a robust conceptual representation of the ocean circulation system.

At the same time, modern trust in science has not merely been conjured by its data-intensive technologically sophisticated nature, as curiosity about floating ducks can also serve this function. But quantification and systematization have a predictive power, their application often entails other kinds of power, much of which provides cognitive (perceived) security. In the long term, this would become conceptually adopted by the Chinese and translated into maritime practice (Xiang 2010). Continental geopolitics, scientific advancement and different levels of global exploration required comprehensive approaches that were infused by recognizing an increasing importance of in-depth studies forged by unknown amounts of data.

Today, much global change research takes place with a supposed detachment from values and policies, even as it is channelled into contributing to politics of global change. Quantitative trajectories of future socio-environmental pathways - leading to utopias and dystopias alikeare described as model outputs. These values are merely occluded, and the relationship between hidden agendas and power is often complex. Unsurprisingly, global change research occasionally faces issues relating to public trust in Western-style mathematics-based science. But as its output increasingly informs policy making, the need to probe, illuminate and (self-)critique grows rather than vanishes. As society today faces many new scale global challenges, it might be useful to remember that scientific measurement and prediction are just part of the process. Just as global change during the Sattelzeit equally demanded changes fostering change in science, today's science might profit from self-reflecting on facing a similar threshold: by reversely integrating broad general knowledge and understanding beyond the personal level, while granting a meaningful use of numbers and data deeply connected with the present and past lived experience as well as basic personal observation. Maybe a few rubber ducks are all that is needed. 


\section{Note}

1. Quoted in Bravo (1999), 182, FN 36.

\section{REFERENCES}

Anderson, Katherine. 2007. Predicting the Weather: Victorians and the Science of Meteorology. Chicago: University of Chicago Press.

Batten, Charles. 1990. Literary Responses to the Eighteen Century Voyages. In Background to Discovery: Pacific Exploration from Dampier to Cook, ed. Derek Howse, 128-159. Berkeley: University of California Press.

Baugh, Daniel. 1990. Seapower and Science: The Motives for Pacific Exploration. In Background to Discovery: Pacific Exploration from Dampier to Cook, ed. Derek Howse, 1-55. Berkeley: University of California Press.

. 1993. James Rennell. Antiquarian of Ocean Currents. Ocean Challenge 4: $41-52$.

- 1999. Precision and Curiosity in Scientific Travel: James Rennell and the Orientalist Geography of the New Imperial Age (1760-1830). In Voyages and Visions: Towards a Cultural History of Travel, ed. Jas Elsner, 162-183. London: Reaction Books.

Carozzi, Albert. 1964. Lamarck's Theory of the Earth. Hydrogeologie. Isis 55 (3): 293-330.

Cawood, John. 1979. The Magnetic Crusade. Isis 70: 493-518.

Chaplin, Joyce. 2007. The First Scientific American: Benjamin Franklin and the Pursuit of Genius. New York: Perseus.

Clerkin, Ben. Thousands of Rubber Ducks to Land on British Shores After 15 year Journey. Daily Mail Online, 27 June, 2007. http://www.dailymail. co.uk/news/article-464768/Thousands-rubber-ducks-land-British-shores15-year-journey.html. Accessed 12 Aug 2015.

Charnock, Henry, and M. Deacon. 2001. Introduction. Ocean Circulation. In Understanding the Oceans: A Century of Ocean Exploration, ed. Henry Charnock and Margaret Deacon, 155-157. London: Routledge.

Corbin, Alain. 1994. The Lure of the Sea: The Discovery of the Seaside in the Western World, 1750-1850. Cambridge: Polity.

Cornell, Sarah. 2013. Commentary. In The Future of Nature. Documents of Global Change, ed. Libby Robin et al., 442-444. New Haven: Yale University Press.

Deacon, Margaret. 1985. An Early Theory of Ocean Circulation. J.S. Von Waitz and his Explanation of the Currents in the Street of Gibraltar. Progress in Oceanography 14: 89-101.

- 1997. Scientists and the Sea. London: Ashgate.

Dettelbach, Michael. 1996. Humboldtian Science. In Cultures of Natural History, ed. Nicolas Jardine, 287-304. Cambridge: Cambridge University Press. 
Deng, Gang. 1997. Chinese Maritime Activities and Socioeconomic Development, c. 2100 B.C.-1900 A.D. Westport: Greenwood Press.

Ebbesmeyer, Carl. 2009. Flotsametrics and the Floating World: How One Man's Obsession with Runaway Sneakers and Rubber Ducks Revolutionized Ocean Science. New York: Harper Collins.

Gould, James. 1993. James Rennell's View of the Arctic Circulation. A Comparison with our Present Knowledge. Ocean Challenge 4: 26-33.

Granados, Ulises. 2012. Modernization and Regionalism in South China: Notes on Costal Navigation in Guangdong Province During the Late Nineteenth and Early Twentieth Century. International Journal of Maritime History 24 (1): 89-114.

Greenblatt, Stephen. 1988. Shakespearian Negotiations: The Circulation of Social Energy in Renaissance England. Berkeley: University of California Press.

Griffiths, Gwyn. 1993. James Rennell and William Scoresby. Their Separate Quest for Accurate Current Data. Ocean Challenge 4: 34-40.

Heunemann, Julia. 2014. No Straight Lines. Zur Kartographie des Meeres bei Matthew Fontaine Maury. In Weltmeere. Wissen und Wabrnebmung im langen 19. Jahrhundert, ed. Alexander Kraus and Martina Winkler, 149-168. Göttingen: Vandenhoeck \& Ruprecht.

Hohn, Donovan. 2007. Moby-Duck. Or, the Synthetic Wilderness of Childhood. Harpers Magazine, January 2007. http://harpers.org/ archive /2007/01/moby-duck/. Accessed 12 Aug 2015.

Howse, Derek. 1990. Navigation and Astronomy in the Voyages. In Background to Discovery: Pacific Exploration from Dampier to Cook, ed. Derek Howse, 160-184. Berkeley: University of California Press.

Kortum, Gerhard. 2001. Humboldt und das Meer: Eine Ozeanographiegeschichtliche Bestandsaufnahme. Northeastern Naturalist 8 (1): 91-108.

Markham, Clements. Rennell, James. Dictionary of National Biography (1885-1900): 14-15.

Millar, Sarah Louise. 2013. Science at sea: Soundings and instrumental knowledge in British Polar expedition narratives, c. 1818-1848. Journal of Historical Geography 42 (3): 77-87.

Miller, David. 1983. Between Hostile Camps: Sir Humphry Davy's Presidency, 1820-1827. British Journal for the History of Science 16: 1-47.

- 1986. The Revival of the Physical Sciences in Britain, 1815-1840. Osiris 2: 107-134.

Needham, Joseph. 1959. Science and Civilization in China. Vol. 3: Mathematics and the Sciences of the Heavens and the Earth. Cambridge: Cambridge University Press.

- 1962. Science and Civilization in China. Vol 4: Physics and Physical Technology. Part 1: Physics. Cambridge: Cambridge University Press. 
1971. Science and Civilization in China. Vol 4: Physics and Physical Technology. Part 3: Civil Engineering and Nautics. Cambridge: Cambridge University Press.

Petterson, R.G., L. Stramma, and G. Kortum. 1996. Early Concepts and Charts of Ocean Circulation. Progress in Oceanography 37: 1-133.

Pollard, R. 1993. James Rennell. Father of Oceanography. Ocean Challenge 4: $24-25$.

Pomeranz, Kenneth. 2000. The Great Divergence: China, Europe, and the Making of the Modern World Economy. Princeton: Princeton University Press.

Ptak, Rudolf. 2006. The Sino-European Map (Shanhai yudi quantu) in the Encyclopaedia Sancai tuhui. In The Perception of Maritime Space in Traditional Chinese Sources, ed. Angela Schottenhammer and Rudolf Ptak, 191-207. Wiesbaden: Harrassowitz.

- 2007. Die maritime Seidenstraße. Küstenräume, Seefahrt und Handel in vorkolonialer Zeit. Munich: C.H. Beck.

Reidy, Michael. 2008. Tides of History. Ocean Science and Her Majesty's Navy. Chicago: University of Chicago Press.

Reinhard, Wolfgang. 2014. Die Geschichte der Welt 1350-1750: Weltreiche und Weltmeere. Munich: C.H. Beck.

Rennell, James. 1781. A Bengal Atlas: Containing Maps of the Theatre of War and Commerce on that Side of Hindoostan. London.

- 1832. An Investigation of the Currents of the Atlantic Ocean, and Those Who Prevail Between the Indian Ocean and the Atlantic Ocean, ed. J. Purdy. London. Digital file [ibooks reader 4.3, 75lp]. Retrieved from http://www. en.bookfi.org.

Rodd, Rennell. 1930. Major James Rennell. Born 3 December 1742. Died 20 March 1830. The Geographical Journal 75 (4): 289-299.

Rozwadowski, Helen. 1996. Small World: Forging a Scientific Maritime Culture for Oceanography. Isis 87 (1): 409-429.

. 2008. Fathoming the Ocean. The Discovery and Exploration of the Deep Sea. Cambridge: Belknap.

Rupke, Nicholas. 2001. Humboldtian Distribution Maps: The Spatial Ordering of Scientific Knowledge. In The Structure of Knowledge: Classification of Science and Learning Since the Renaissance, ed. Tore Frängsmyr, 93-116. Berkeley: Office for History of Science and Technology.

Salomon, Claudine. 2006. Coastal Maps from the Beginning of the Qing Dynasty, With Special Reference to the Qingchu haijiang tushuo. In The Perception of Maritime Space in Traditional Chinese Sources, ed. Angela Schottenhammer and Rudolf Ptak, 177-189. Wiesbaden: Harrassowitz.

Schaffer, Simon. 1986. Scientific Discoveries and the End of Natural Philosophy. Social Studies of Science 16 (3): 387-420. 
Schlee, Susan. 1973. On the Edge of an Unfamiliar World: A History of Oceanography. New York: Duttoon.

Schottenhammer, Angela. 2012. The 'China Seas' in World History. A General Outline of the Role of Chinese and East Asian Maritime Space from its Origins to c. 1800. Journal for Marine and Island Cultures 1: 63-86. doi:10.1016/j.imic.2012.11.002.

Van der Schrier, G., and S.L. Weber. 2006. The Gulf Stream and Atlantic SeaSurface Temperatures in AD 1790-1825, 1-28. De Bilt: Royal Netherlands Meteorological Institute (KNMI).

Williams, Glyn. 2013. Naturalists at Sea. Scientific Travellers from Dampier to Darwin. New Haven: Yale University Press.

Worster, Donald. 2016. Shrinking the Earth: The Rise and Decline of American Abundance. New York: Oxford University Press.

Xiang, Jianhai. 2010. Marine Science and Technology in China: A Roadmap to 2050. Berlin: Springer.

Zurndorfer, Harriet. 2016. Oceans of History, Seas of Change: Recent Revisionist Writing in Western Languages About China and East Asian Maritime History During the Period 1500-1630. International Journal of Asian Studies 13 (1): 61-94. doi:10.1017/S1479591415000194.

Open Access This chapter is licensed under the terms of the Creative Commons Attribution 4.0 International License (http://creativecommons.org/licenses/ by $/ 4.0 /$ ), which permits use, sharing, adaptation, distribution and reproduction in any medium or format, as long as you give appropriate credit to the original author(s) and the source, provide a link to the Creative Commons license and indicate if changes were made.

The images or other third party material in this chapter are included in the chapter's Creative Commons license, unless indicated otherwise in a credit line to the material. If material is not included in the chapter's Creative Commons license and your intended use is not permitted by statutory regulation or exceeds the permitted use, you will need to obtain permission directly from the copyright holder.

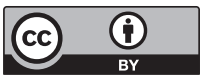

